JEEMAN JUNG and ROBERT J. SHILLER

COWLES FOUNDATION PAPER NO. 1183

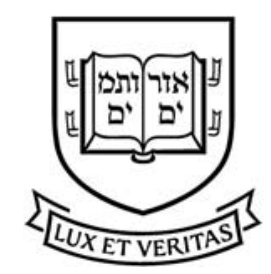

COWLES FOUNDATION FOR RESEARCH IN ECONOMICS

YALE UNIVERSITY

Box 208281

New Haven, Connecticut 06520-8281

2006

http://cowles.econ.yale.edu/ 


\title{
SAMUELSON'S DICTUM AND THE STOCK MARKET
}

\author{
JEEMAN JUNG and ROBERT J. SHILLER*
}

\begin{abstract}
Samuelson has offered the dictum that the stock market is "micro efficient" but "macro inefficient." That is, the efficient markets hypothesis works much better for individual stocks than it does for the aggregate stock market. In this article, we review a strand of evidence in recent literature that supports Samuelson's dictum and present one simple test, based on a regression and a simple scatter diagram, that vividly illustrates the truth in Samuelson's dictum for the U.S. stock market data since 1926. (JEL G14)
\end{abstract}

\section{INTRODUCTION}

Paul A. Samuelson has argued that one would expect that the efficient markets hypothesis should work better for individual stocks than for the stock market as a whole:

Modern markets show considerable micro efficiency (for the reason that the minority who spot aberrations from micro efficiency can make money from those occurrences and, in doing so, they tend to wipe out any persistent inefficiencies). In no contradiction to the previous sentence, I had hypothesized considerable macro inefficiency, in the sense of long waves in the time series of aggregate indexes of security prices below and above various definitions of fundamental values. ${ }^{1}$

We shall see in this article that there is now substantial evidence supporting Samuelson's dictum where market inefficiency is defined as predictability of future (excess) returns. We will also present a new test and scatter diagram that clarifies the truth in this dictum.

Samuelson's dictum is plausible if there is much more information available to the market about future changes in fundamentals (the

*We are indebted to John Y. Campbell, Erik Hjalmarsson, Paul A. Samuelson, and Tuomo Vuolteenaho for comments. Ana Fostel provided research assistance.

Jung: Associate Professor, Division of Economics and International Trade, Sangmyung University, Seoul 110 743 Korea. Phone 822-2287-5189, Fax 822-3965-702, E-mail jmjung@sangmyung.ac.kr

Shiller: Professor, Cowles Foundation for Research in Economics, International Center for Finance, Yale University. 30 Hillhouse Ave., New Haven, CT 06520. Phone 1-203-432-3708, Fax 1-203-432-6167, E-mail robert.shiller@yale.edu

1. This quote is from a private letter from Paul Samuelson to John Campbell and Robert Shiller. The quote appears and is discussed in Shiller (2001, p. 243). Samuelson has been making this point for many years; it is also made in Samuelson (1998). dividends or earnings or cash flows) of individual firms than there is about future changes in the fundamentals of the aggregate stock market. Individual firms' activities are highly diverse: Some have breakthrough discoveries or important new patents; others are in declining industries or have fundamental structural problems. Hence some firms at some times may be well known to the market to have a highly positive expected growth of fundamental value, whereas different firms or the same firms at different times may be well known to the market to have a highly negative expected growth of fundamental value. If there is enough variation in information that the market has about future fundamental growth of individual firms, then these variations might then be big enough to swamp out the effect on price of time variation in other factors, such as speculative booms and busts, making the simple efficient markets model work fairly well as an approximation for individual firms.

In contrast, there would seem not to be the same kind of clarity in the market about changes in the aggregate dividend or earnings flow for the stock market of a country. Changes in these flows for the aggregate stock are less dramatic than for individual firms, because the aggregate averages out the individual stories of the firms and the reasons for changes in the aggregate are more subtle and harder for the investing public to understand, having to do with national economic

\section{ABBREVIATIONS}

CRSP: Center for Research on Security Prices

Economic Inquiry

(ISSN 0095-2583)

Vol. 43, No. 2, April 2005, 221-228 doi:10.1093/ei/cbi015

(c) Western Economic Association International 
growth, stabilizing monetary policy, and the like. If changes in aggregate dividends are harder to predict, we might then expect that factors other than information about fundamentals, factors such as stock market booms and busts, would swamp out the effect of information about future dividends in determining price and make the simple efficient markets model a bad approximation for the aggregate stock market.

\section{EVIDENCE IN THE LITERATURE FOR SAMUELSON'S DICTUM}

There is now substantial evidence in the published literature for Samuelson's dictum. One of us (Shiller 1981) presented evidence that was interpreted as finding evidence of "excess volatility" in the stock market relative to the efficient markets model using U.S. data 1871-1979 (see also LeRoy and Porter 1981; Campbell 1991). The same methods did not find much evidence of inefficiency in other principal components of industry stock market indexes over the same time interval (Shiller 1989, ch. 11). In this sense, the aggregate market was found to be inefficient and the industry deviations from the aggregate market were not found to be inefficient.

To deal with criticisms that these early efforts to detect excess volatility made inappropriate assumptions about stationarity around trend, Campbell and Shiller (1988 a,b) derived a cointegrated model for dividend, price, and earnings, a model that was then recast as a vector autoregression in the log dividend-price ratio, the change in log dividends, and the log earnings-price ratio. Applying this model to the aggregate U.S. stock market 1871-1987, they concluded that only about $7 \%$ of the variance of annual stock market returns can be justified in terms of new information about future dividends.

Vuolteenaho (2002) extended the CampbellShiller framework in such a way that it could be used to produce a decomposition of unexpected excess returns of a firm into a component due to information about future cash flows of the firm (what we will call the efficient market component) and a component due to information about future returns (what we will call the inefficient market component of returns). Vuolteenaho studied 36,791 firmyears of data for the United States 1954-96. He found, based on a vector-autoregressive analysis, that about $75 \%$ of the variance of (unexpected) annual firm stock excess returns can be justified in terms of the efficient market component.

Vuolteenaho also estimated the standard deviation of the "atypical discount" (the difference between the log stock price and the log value that is justified by fundamentals as he measures them) to be about $25 \%$. Vuolteenaho concludes that even though he found that most of the variance of returns can be justified in terms of fundamentals, the inefficient component of stock price variation that generates predictable movements in future returns "still has an economically significant impact on firm-level stock prices" (p. 246). Samuelson's dictum asserts that individual-firm stock price variations are dominated by genuine information about future cash flows of the firm, but they are not perfect indicators of these cash flows either.

Cohen et al. (2001) used a method similar to that in Vuolteenaho (2002) to derive a decomposition of the cross-portfolio variance of the log ratio of book value to market value into three components: a component that could be justified in terms of information about future cash flow, a component related to the persistence of the value spread, and what we might call an "inefficiency component" that generates predictable future returns. ${ }^{2}$ They also used a longer sample period, an international data set, and some improvements in method. Their conclusions with U.S. data 1937-97 and 192,661 firmyears were that $80 \%$ of the cross-sectional variance in the log ratio of book value to market value can be justified by the first few components, only $20 \%$ by the inefficiency component that explains 15-year returns. Their conclusion with international data on 22 countries 1982-98 and 27,913 firm-years was that $82 \%$ of the cross-sectional variance of bookto-market values was explained by the first two components, and only $18 \%$ by the inefficiency component that explains five-year returns.

2. Cohen et al. (2001) assembled firms into portfolios and looked at cross-portfolio variance rather than crossfirm variance. They did this because their (logarithmic) model does not allow zero or negative book values, but individual firms sometimes have these. In this article, we would have a similar problem with zero dividends, for which a log is not defined, but we do not use a logarithmic model. 
The Campbell-Shiller results, the Vuolteenaho results, and the Cohen et al. results together make a case for Samuelson's dictum: Campbell and Shiller found that little of the variability of aggregate stock market returns are explained by fundamentals, whereas Cohen and colleagues found that much of the variability of individual stock returns or ratios of book value to market value are explained by fundamentals.

\section{A FURTHER DEMONSTRATION OF SAMUELSON'S DICTUM}

We now show a simple demonstration of evidence for Samuelson's dictum without any of the paraphernalia of vector autoregressions, which introduce assumptions about the stochastic properties of the variables under analysis, and we will do this by following individual firms for a long time, avoiding making any assumptions that the outlook for one firm can be inferred by data on other firms. ${ }^{3}$

We will show evidence that most of the variability of the individual-firm stock price relative to one measure of fundamental value, the dividend, can be justified in terms of information about future changes in dividends. We will do this by a simple regression of future dividend changes on the dividend price ratio, proving that this ratio substantially correctly forecasts the future growth rate of dividends and hence that variations of price relative to dividends are largely justified in terms of market efficiency

Assuming a constant discount rate but varying growth rate of real dividends, the dividendprice ratio $D_{t} / P_{t}$ can be derived from the simple expected present value relation with discount rate $r$ as

$$
\begin{aligned}
D_{t} / P_{t} & =r-E_{t} g_{t}^{D}, \text { where } g_{t}^{D} \\
& =\sum_{k=1}^{\infty}\left(\Delta D_{t+k} / P_{t}\right) /(1+r)^{k-1} .
\end{aligned}
$$

$P_{t}$ is the real (inflation corrected) stock price at the end of year $t, D_{t}$ is the real dividend during the year $t, \Delta D_{t}=D_{t}-D_{t-1}, r$ is the discount

3. Cohen et al. (2001) also use an approach that does not rely on vector autoregressive returns, based on truncated log-linearized present values extending as far into the future as 15 years. The lumping of firms into portfolios means that Cohen and collegues were not following individual firms through time as we do. factor used in the present value formula for stock prices, and $E_{t}$ denotes expectation conditional on information at time $t .^{4}$

Note that in the equation $g_{t}^{D}$, representing a dividend growth rate, is expressed as the sum of discounted amounts of future dividend changes from a $\$ 1$ investment at time $t .5$ In other words, the growth rates are computed relative to price $P$ rather than $D$, and this is important because with individual firms there are in fact some zero dividends, and so growth rates of dividends themselves could not be calculated. The equation can be viewed as a dynamic counterpart of the Gordon model, $D /$ $P=r-g$, where $g$ is the constant expected dividend growth rate.

We could in theory evaluate this model, after turning the efficient markets equation around to $E_{t} g_{t}^{D}=r-D_{t} / P_{t}$, by regressing, with time-series data, $g_{t}^{D}$ onto a constant and the dividend price ratio $D_{t} / P_{t}$, and testing the null hypothesis that the coefficient of $D_{t} / P_{t}$ is minus one. Such a test of the efficient markets hypothesis would be recommended by its simplicity and immediacy. There is, however, the practical difficulty that the summation extends to infinity and so the right-hand side can never be computed with finite data. Most of the studies cited solved this problem by inferring the summation using an autoregressive model. A simpler and more direct way, without adding the additional assumptions implicit in the vector autoregressive model, is to approximate the right-hand side and run a regression of the approximated right-hand side onto the dividend price ratio. This was done in Campbell and Shiller (1998, 2001) for aggregate stock market indexes. Campbell and Shiller (2001) regressed 10-year log dividend growth rates $\ln \left(D_{t+10} / P_{t}\right)$ onto $\ln \left(D_{t} / P_{t}\right)$ with annual Standard \& Poor composite stock price data using the long time-series data of 1871 to 2000 . The coefficient of

4. Note that efficient markets theory implies (1) even if firms repurchase shares in lieu of paying as much dividends, the share repurchase has the effect of raising subsequent per-share dividends.

5. Campbell and Shiller (1988a,b) used a logapproximation of the dividend-price model as follows:

$$
\begin{aligned}
\log \left(D_{t} / P_{t}\right) & =E_{t} \log \left(D_{t} / P_{t}\right)^{*} \text { where } \log \left(D_{t} / P_{t}\right)^{*} \\
& =-\sum_{j=1}^{\infty} \rho^{j-1} \Delta \log D_{t+j}+C .
\end{aligned}
$$

The formula is closely analogous to equation (1) in this article. 
$\ln \left(D_{t} / P_{t}\right)$ turned out to be positive, to have the wrong sign. The result was interpreted as indicating that in the entire history of the U.S. stock market, the dividend-price ratio has never predicted dividend growth in accordance with the simple efficient markets theory.

\section{RUNNING THE REGRESSION WITH INDIVIDUAL STOCK DATA}

A fundamental problem with testing this model with individual stock data is, as we have noted, that although the model concerns growth rates of dividends over a time range extending from decade to decade, there are not many firms that survive for many decades. In fact, when we did a search on the Center for Research on Security Prices (CRSP) tape, we found that there were only 49 firms that appear on the tape continuously without missing information during the period of 1926 to $2001 .{ }^{6}$ Because the number of surviving firms is so small, there is a risk that they are atypical, not representative of all firms. This risk must be borne in mind in evaluating our results, but we believe that looking at this the universe of surviving U.S. firms on the CRSP tape still offers some substantial insights, at least as a case study. Note that the mere fact of survival would be expected if anything to put an upward bias on the average return on the stocks. It would have no obvious implication for either the time-series or cross-sectional ability of the dividend-price ratio to predict future changes in dividends.

Using monthly data from the CRSP tape, we create the series of annual dividends, $D_{t}$, by summing up 12 monthly dividends from January to December of the year; the price

6. When Poterba and Summers (1988) did a similar search of the CRSP tape, they found 82 survival firms during the $1926-85$ period. The smaller number here apparently reflects the continuing disappearance of firms through time. Though the number of firms is small, we observe that they span a wide variety of industries. Among the 49 firms, there are 31 manufacturing firms, 5 utility companies, 5 wholesale and retails, 3 financial firms, 4 mines and oil companies and 1 telecommunication company.

7. The results are invariant to the starting month for the calculation of annual dividends. We also work on the same estimation using the data of survival firms after World War II. There are 125 firms that have existed during the 1949-2001 period without any missing information on stock prices and dividends. The results of the regressions on these samples are basically similar to those reported in the article.
$P_{t}$ is for the end of the year. ${ }^{7}$ We exclude from the series nonordinary dividends due to liquidation, acquisition, reorganization, rights offering, and stock splits. All the dividends and stock prices are adjusted by the proper price adjustment factors obtained from the CRSP tape and then are expressed in real terms using the Consumer Price Index. As a proxy for the future dividend growth $g_{t}^{D}$ we use $\hat{g}_{t}^{D}$, the summation truncated after $K$ years:

$$
\hat{g}_{t}^{D}=\sum_{k=1}^{K}\left(\Delta D_{t+k} / P_{t}\right) /(1+r)^{k-1},
$$

and we set $r$ equal to 0.064 , which is the annual average return over all firms and dates in the sample. ${ }^{8}$

To confirm statistical significance, we regress $\hat{g}_{t}^{D}$ onto a constant and $D_{t} / P_{t}$ with the 49 individual firm data in three different ways: (A) separately for each of the 49 firms (49 regressions each with $76-K$ observations), (B) pooled over all firms with a dummy for each firm (one stacked regression with $49 \times[76-K]$ observations), and (C) for the equally weighted portfolio composed of the 49 firms (one regression with $76-K$ observations). Table 1 shows the three results for $K=10$, 15,20 , and 25 , while for the pooled regression, $K=75$ is also shown. When appropriate, $t$ statistics were computed using a HansenHodrick (1980) procedure to correct these statistics for the effects of serial correlation in the error term due to the overlapping 10-, 15-, 20-, or 25-year intervals with annual data. For the stacked regressions (B) for $K=10,15,20$, and 25, the Hansen-Hodrick procedure was modified to take account as well of contemporaneous correlation of errors across firms. ${ }^{9}$

If there were no problem of survivorship bias and if the truncation of our infinite sum for $\hat{g}_{t}^{D}$ were not a problem, then we would expect, assuming the simple efficient markets

8. We avoid the common practice of using the terminal price, $P_{t+K}$ to infer dividend changes beyond $t+K$ (as Cohen et al. 2001 essentially did) because that would bring us back to using a sort of return variable as the dependent variable in our regressions; we want our method to have a simple interpretation, here just whether the dividendprice ratio predicts future dividend growth.

9. The variance matrix $\Omega$ of the error term in the stacked regression, for computation of the variance matrix of the coefficients $\left(X^{\prime} X\right)^{-1}\left(X^{\prime} \Omega X\right)(X X)^{-1}$ consists of $49 \times$ 49 blocks, one for each firm pair. Each block has the usual Hansen-Hodrick form, but we allow for cross-covariance in the off-diagonal blocks. 
TABLE 1

Results for Regressions of Future Dividend Growth on Current Dividend-Price Ratio:

\begin{tabular}{|c|c|c|c|}
\hline & Coefficient of $D_{t} / P_{t}$ & $t$-Statistic & $r^{2}$ \\
\hline \multicolumn{4}{|l|}{ A. Average of 49 separate regressions } \\
\hline i. $K=10, n=66$ each regression & -0.440 & -2.11 & 0.182 \\
\hline ii. $K=15, n=61$ each regression & -0.498 & -1.85 & 0.167 \\
\hline iii. $K=20, n=56$ each regression & -0.490 & -1.67 & 0.173 \\
\hline iv. $K=25, n=51$ each regression & -0.499 & -1.55 & 0.162 \\
\hline \multicolumn{4}{|l|}{ B. Pooled over all firms } \\
\hline i. $K=10, n=3,234$ & -0.589 & -5.91 & 0.174 \\
\hline ii. $K=15, n=2,989$ & -0.648 & -5.69 & 0.217 \\
\hline iii. $K=20, n=2,744$ & -0.666 & -4.82 & 0.216 \\
\hline iv. $K=25, n=2,499$ & -0.711 & -4.84 & 0.149 \\
\hline v. $K=75, n=49$ & -1.087 & -1.41 & 0.041 \\
\hline \multicolumn{4}{|l|}{ C. Using the portfolio of the 49 firms } \\
\hline i. $K=10, n=66$ & 0.336 & 1.79 & 0.084 \\
\hline ii. $K=15, n=61$ & 0.322 & 1.52 & 0.063 \\
\hline iii. $K=20, n=56$ & 0.463 & 1.84 & 0.101 \\
\hline iv. $K=25, n=51$ & 0.697 & 2.40 & 0.175 \\
\hline
\end{tabular}

model, that the slope in the regressions should be minus one and the intercept be the average return on the market. In fact, the truncation of the infinite sum means that the coefficient might be something other than minus one. Hence, we merely test here for the negativity of the coefficient of the dividend-price ratio, looking only to see if it is significant in predicting future dividend changes in the right direction. Because of survivorship bias, the fact that we are looking only at surviving firms would appear to put a possible upward bias on the intercept, and therefore we do not focus on the intercept here.

Table 1 part A reports the summary result of the 49 individual regressions. For $K=10$, the average coefficient and the average $t$-statistic on $D_{t} / P_{t}$ are -0.440 and -2.11 , respectively. We find that for $K=10,42$ out of the 49 firms had negative coefficients as predicted by the theory, that is, the dividend price ratio does predict future changes in dividends in the right direction for the simple efficient markets model, and 20 of the coefficients are statistically significant at $5 \%$ significance level. ${ }^{10}$ As $K$ is increased, the average $t$-statistic and $r^{2}$ decrease. The coefficient of $D / P$ always has the negative coefficient predicted by the simple efficient markets model, though far from -1.00 . Thus,

10. Those results, not reported in the table to conserve the space, are available on request.
$D / P$ does seem to forecast future dividend growth, although the coefficient is shrunken from minus one toward zero, as one might expect if there is some extraneous noise $D / P$ (caused, say, by investor fads), causing an errors-in-variables bias in the coefficient.

Table 1 Part B shows the results when the regressions were pooled, so that there are (except where $K=75$ ) many more observations in the regression than in Part A and hence more power to the test. In the $K=75$ case, the limiting case with our 76 annual observations, the regression reduces to a simple cross-section regression of the 49 firms for $t=1926$. Since there are only 49 observations in the $K=75$ case, the test is not powerful here, and we report it only for completeness. For $K=10$, 15,20 , and 25 the $t$-statistic is highly significant and negative. As $K$ is increased, the coefficient of the dividend-price ratio decreases, and at $K=75$, the coefficient is very close to its theoretical value of -1.00 (though poorly measured because only $1926 \mathrm{D} / \mathrm{P}$ are used). These results provide impressive evidence for the simple efficient markets model as applied to individual firm data in the sense that the estimated coefficients are significantly negative, though usually above minus one.

Table 1 Part $\mathrm{C}$ shows the results when the regressions were put together into one regression (by using an equally weighted portfolio) so that we can test the simple efficient markets 
model as applied to an index of the 49 stock prices. The coefficient of the dividend-price ratio has a positive sign, the wrong sign from the standpoint of the simple efficient markets model, and is no longer statistically significant except for $K=25$. The wrong sign mirrors the negative result for the efficient markets model that Campbell and Shiller (1988a) found with a much broader stock market index.

The $t$-statistics reported for Part C are for the null hypothesis that the coefficient of $D /$ $P$ is zero; the statistics are much larger against the efficient markets hypothesis that the coefficient equals minus one. However, there is an issue that the distribution of our $t$-statistics may not approximate the normal distribution if $D / P$ is nonstationary or nearly so. Although our financial theory suggests that the dividend yield should be stationary, in fact the dividend yield is at best slowly mean-reverting. There is a subtle econometric issue here, for which there is a variety of proposed solutions in the literature, and it is not central to this article to try to resolve it. Elliott and Stock (1994) show that the size distortion in the $t$-statistic caused by near-unit root behavior may be substantial. Campbell and Yogo (2002) show, however, that if we rule out explosive processes for the dividend-price ratio in regres- sions like those of part C, there is good evidence against market efficiency.

We interpret these results as confirming the Samuelson dictum. In our results, there is evidence that individual firm dividend-price ratios predict future dividend growth in the right direction, but no evidence that aggregate dividend-price ratios do.

\section{A LOOK AT THE DATA SHOWS HOW $D_{t} / P_{t}$ PREDICTS FUTURE FUNDAMENTALS}

When running a regression, it is always important to look at the data to check whether some anomalous reason exists for the fit. Here, we look at a scatter diagram to see, for example, whether our results are driven primarily by observations in a certain range (such as zero dividend-price ratios) or is driven by a few outliers that might reflect unusual circumstances.

Figure 1 shows a scatter diagram of $\hat{g}_{t}^{D}$ for $K=25$ against $D_{t} / P_{t}$ for all 2,499 observations, that is, for all 49 firms and for $t=$ 1926 to 1976 (1976 being the last year for which 25 subsequent years are available). The range of $D_{t} / P_{t}$ is from 0.000 to 0.400 several times as wide as the range (from 0.022 to 0.099 ) of the dividend-price ratio

FIGURE 1

Scatter Diagram Showing Dividend Price Ratio $D_{t} / P_{t}$, Horizontal Axis, and Subsequent 25-Year Dividend Growth $\left(\hat{g}_{t}^{D}\right)$ (Equation 2, $K=25$ ), Vertical Axis, Note: 2,499 observations shown, comprising 49 firms, $t=1926$ through 1976

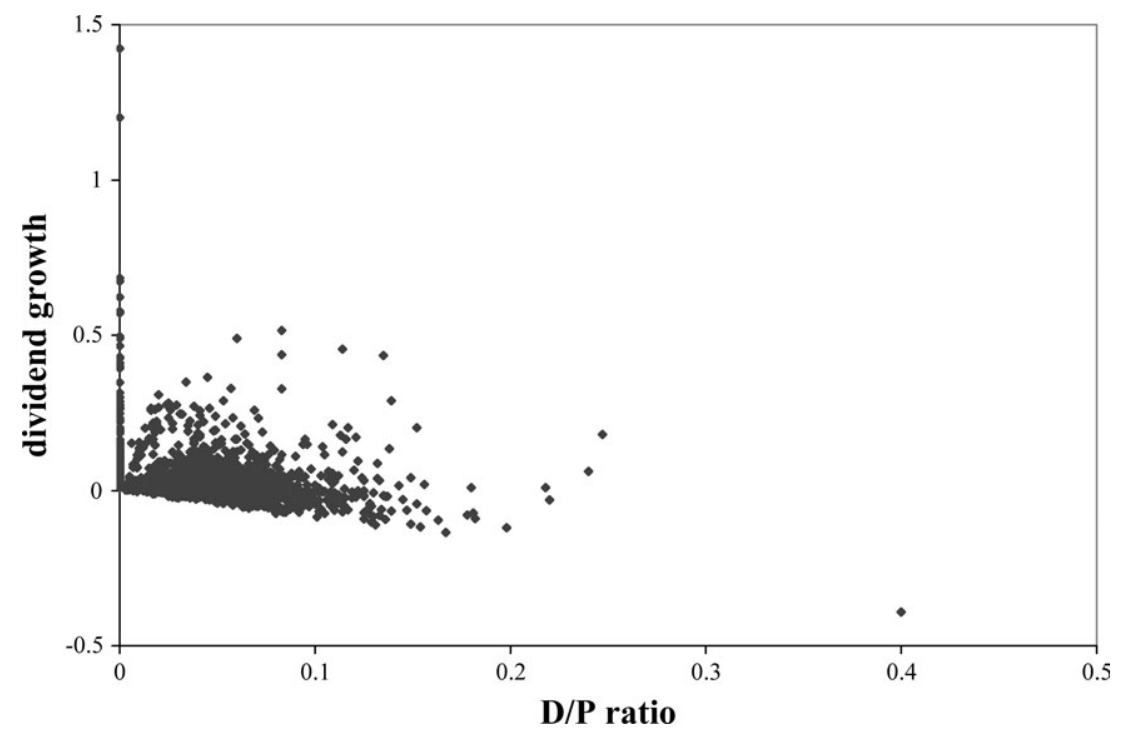


for the aggregate stock market over the sample period. The sharply reduced range of the dividend-price ratio for the aggregate stock market would itself be a strong reason to suspect that the simple efficient markers model will perform less well for it when compared with individual firms.

Over this entire range, there is a distinct negative slope to the curve as the efficient markets theory would predict: Firms with lower dividend-price ratios did indeed have higher subsequent dividend growth, offering some evidence for micro-efficiency. Plots for $K=$ 10, 15, and 20 look very similar to Figure 1.

One should be cautious in interpreting this diagram, however. Note that by construction all points lie on or above a line from $(0,0)$ with a slope of minus one, reflecting the simple fact that dividends cannot go below zero. The efficient markets model and our assumption that dividends beyond $K$ years into the future cannot be forecasted instead says that the scatter should cluster around a line from $(0, r-c)$ with a slope of minus one, a line that lies above the other line and is parallel with it, where $c$ is the mean of the truncated portion of the present value formula, as well as any possible survivorship bias. But our results are not guaranteed by construction. Indeed when the scatter of points for the aggregated firms (corresponding to the third regressions, Part $\mathrm{C}$ in Table 1) is plotted, it lies above this line but does not have a negative slope.

This line from $(0,0)$ with a slope of minus one is easily spotted visually as the lower envelope of the scatter of points. Any observation of $D_{t} / P_{t}$ that is followed by a dramatic drop in dividends (to approximately zero for $K$ years) will lie approximately on this line. Some of the most visible points on the scatter represent such firms. For example, the extreme right outlier on the scatter, representing Schlumberger in 1931, represents nothing more than a situation in which the firm attempted to maintain its dividend level in spite of rapidly declining fortunes. Its stock price fell precipitously after the 1929 crash, converting a roughly $8 \%$ dividend into a $40 \%$ dividend, which was cut to zero in 1932 and held at zero for many years. This extreme case may be regarded as a victory for the efficient markets model, in that it does show that the dividendprice ratio predicts future dividend growth, though not the usual case we think of when we consider market efficiency. It is plain from the fact that the points are so dense around the lower envelope line that much of the fit derives from firms whose dividends dropped sharply.

Another simple story is that of firms that pay zero dividends. Note that all firm-year pairs with zero dividends can be seen arrayed next to the vertical axis and that the dividend growth for these firms tends to be higher than for the firms with nonzero dividends, as the simple efficient markets model would predict. Firms with zero dividends showed higher dividend growth as measured by $\hat{g}_{t}^{D}$ : the mean $\hat{g}_{t}^{D}$ for the zero-dividend observations is 0.149 , which is greater than $r=0.064$, possibly reflecting the selection bias for surviving firms noted. The fact that these points along the vertical axis cluster above 0.064 might also be considered a sort of approximate victory for market efficiency. Also note that even if we deleted these firms, there still is a pronounced negative slope to the scatter. The predictive ability of the simple efficient markets model is not just due to the phenomenon of zero dividends.

Even if we delete all observations of zero dividends, and look at dividend price ratios less than the discount rate $r$, that is, less than 0.064 , then the slope of the regression line for $K=25$ changes to -0.479 , not much closer to zero. This means that there are also observations of a low but non zero dividend-price ratio successfully predicting above normal dividend growth.

Regression diagnostics following Belsley et al. (1980) revealed that no particularly influential observations were responsible for the results in the pooled regressions.

\section{SUMMARY}

There is now substantial evidence in the literature, based on vector autoregressive methodology, in favor of Samuelson's dictum. In this article, we augmented this evidence using data on long-surviving firms and a very direct approach to examining market efficiency. With these data on the universe of U.S. individual firms on the CRSP tape with continuous data since 1926, Samuelson's dictum appears to have had some validity. Over the interval of U.S. history since 1926, individualfirm dividend-price ratios have had some significant predictive power for subsequent growth rates in real dividends; this is evidence of micro-efficiency. A look at a scatter plot of the data confirms that this result is not exclusively due to firms paying zero dividends. 
When the firms are aggregated into an index, the dividend-price ratio gets the wrong sign in the regressions and is usually insignificant. If anything, high aggregate dividendprice ratios predict high aggregate dividend growth, and so there is no evidence of macro-efficiency. ${ }^{11}$

One might interpret these results as saying that the faith that has in the past been expressed for the simple efficient markets model for the aggregate stock market is the result of a faulty extrapolation to the aggregate of a model that did indeed have some value for individual firms.

\section{REFERENCES}

Belsley, D. A., E. Kuh, and R. E. Welsch. Regression Diagnostics: Identifying Influential Data and Sources of Collinearity. New York: Wiley, 1980.

Campbell, J. Y. "A Variance Decomposition for Stock Returns." Economic Journal, 101, 1991, 157-79.

Campbell, J. Y., and R. J. Shiller. "The Dividend-Price Ratio and Expectations of Future Dividends and Discount Factors." Review of Financial Studies, 1, 1988a, 195-228.

- "Stock Prices, Earnings, and Expected Dividends." Journal of Finance, 43, 1988b, 661-76.

-. "Valuation Ratios and the Long-Run Stock Market Outlook." Journal of Portfolio Management, Winter 1998, 11-26.

"Valuation Ratios and the Long-Run Stock Market Outlook: An Update.” NBER Working Paper No. 8221, 2001. (Forthcoming in Advances in Behavioral Finance II, edited by Richard Thaler. New York: Sage Foundation, 2003.)
Campbell, J. Y., and M. Yogo. "Efficient Tests of Stock Return Predictability." Unpublished paper, Harvard University, 2002.

Cohen, R., C. Polk, and T. Vuolteenaho. "The Value Spread." National Bureau of Economic Research Working Paper No. W8242. 2001.

. "DoesRisk or Mispricing Explain the Cross Section of Stock Prices?" Unpublished paper, 2002.

."The Price Is (Almost) Right." National Bureau of Economic Research Working Paper No.10131, 2003.

Elliott, G., and J. H. Stock. "Inference in Time Series Regression When the Order of Integration of a Regressor Is Unknown." Econometric Theory, 10, 1994, 672-700.

Hansen, L. P., and R. J. Hodrick. "Forward Exchange Rates as Optimal Predictors of Future Spot Rates: An Econometric Analysis." Journal of Political Economy, 88, 1980, 829-53.

Jung, J. "Efficiency and Volatility of Stock Markets: Mean Reversion Detected by Covariance Ratios." Unpublished manuscript, 2002.

LeRoy, S., and R. Porter. "The Present Value Relation: Tests Based on Variance Bounds." Econometrica, 49, 1981, 555-74.

Poterba, J. M., and L. H. Summers. "Mean Reversion in Stock Prices: Evidence and Implications." Journal of Financial Economics, 22,1988, 26-59.

Samuelson, P. A. "Summing upon Business Cycles: Opening Address," in Beyond Shocks: What Causes Business Cycles, edited by Jeffrey C. Fuhrer and Scott Schuh. Boston: Federal Reserve Bank of Boston, 1998.

Shiller, R. J. "Do Stock Prices Move Too Much to Be Justified by Subsequent Changes in Dividends?" American Economic Review, 71, 1981, 421-36.

. Market Volatility. Cambridge, MA: MIT Press, 1989.

Irrational Exuberance, 2nd ed. New York: Broadway Books, 2001.

Vuolteenaho, T. "What Drives Firm-Level Stock Returns?" Journal of Finance, 57, 2002, 233-64.

11. Jung (2002) finds using variance and covariance ratio tests that individual stock returns show quite different mean reversion characteristics than do the returns on the portfolio of them. 